\title{
Comparison of hospital staff performance when using desk top analysers for "near patient" testing
}

\author{
A A NANJI,* R POON, I HINBERG \\ From the *Department of Pathology and Laboratory Medicine, University of Ottawa and Ottawa General \\ Hospital; and the Bureau of Radiation and Medical Devices, Health Protection Branch, Ottawa, Canada
}

SUMMARY The quality and reliability of four desk top analysers were evaluated. In the context of an outpatient clinic, intensive care unit, and a mock up of a physician's office. Seventeen nurses, 14 physicians, and 12 medical office personnel took part in the study. The instruments and tests evaluated were Reflotron (glucose, cholesterol, triglycerides, gamma-glutamyl transferase), Seralyzer (creatinine, glucose, potassium, aspartate aminotransferase), Vision (glucose, urea, cholesterol, triglycerides alkaline phosphatase, uric acid), and DT60 (sodium, potassium, glucose, amylase, uric acid and creatinine). Of the 320 tests performed on the Vision, only two differed by more than $10 \%$ between the specialist staff and other groups. For those performed on the Seralyzer, 95 of 254 results differed by more than $10 \%, 19$ of 199 by more than $10 \%$ for the Reflotron, and 50 of 318 by more than $10 \%$ for the DT60. In general, the nurses were more adept at using the analysers than the physicians and medical office personnel.

There are several advanced dry and wet chemistry systems that permit "near-patient" testing.' The principal benefits of this type of testing include the ready availability of results and a reduction in patient waiting time. ${ }^{2}$ These advantages are particularly important in intensive care units, emergency rooms, and outpatient clinics.

As it is unlikely that trained technical staff will be available at each site for test analyses the burden of performing these tests will probably fall on untrained personnel such as nurses, physicians in training, and medical office personnel. There is, however, a general belief that results obtained by untrained staff can be unreliable. ${ }^{3}$ We compared the performance of nurses, physicians, and medical office personnel using four of the available desk top analysers for "near-patient" testing.

\section{Material and methods}

The study was carried out in the outpatient clinic, intensive care unit, and a mock-up of a physician's office at the Ottawa General Hospital and Ontario Cancer Foundation. Seventeen nurses, 14 physicians, and 12 medical office personnel (secretaries, clerks, computer operators) participated. Each was shown how to perform the analysis on each of the analysers by a trained technologist.

Accepted for publication 3 September 1987
The instruments evaluated were the Kodak DT60 analyser (Eastman Kodak, Rochester, New York), the Reflotron analyser (Boehringer Mannheim Canada, Dorval, Quebec), the Ames Seralyser (Ames Division, Miles Laboratories, Elkhart, Indiana) and the Abbott Vision (Abbott Laboratories, Chicago, Illinois).

The Reflotron analyser is a photometer controlled by microprocessor that uses test strips. The strip, which accepts blood, serum, or plasma, is inserted into the analyser and the coloured product of the reaction is measured by the photometer.

The Seralyser is a reflectance photometer and uses test strips. For each test, a different test module is inserted into the analyser. This module identifies the test variables, processes the reflectance signals from the test strip, and calculates the result. The test strips use serum or plasma.

The Vision analyser uses individual test packs into which customised capillary tubes with whole blood, plasma, or serum are inserted. The blood is spun down inside the analyser and mixed with reagents. The absorbance is read by a photometer and the result calculated and printed.

The DT60 uses special slides for performance of tests on serum or plasma. All reactions take place within the multilayered elements of the slide. The bar code reader in the analyser automatically identifies the test to be performed; all processes are controlled by a self contained microprocessor. 
For precision studies we used low and high concentrations of control materials supplied by the manufacturers and those in use in our laboratory. Each control sample was analysed by several different people from each of the groups and at least 15 control samples were measured for each group. The coefficient of variations $(\mathrm{CV})$ were calculated as $\mathrm{CV}=(\mathrm{SD} /$ mean $\times 100)$.

All comparison studies were done with blood, serum, or plasma. The samples were then analysed by both the technical staff and others. For each test we calculated the percentage difference between results obtained by technical staff and the person performing the test. This calculation of difference by percentage gives a better indication of differences than does correlation analysis. To determine whether the imprecision for each test correlated with the correlation of test results the $\mathrm{CV}$ for each test for each group was correlated with the percentage of results for the same test that differed by more than $10 \%$ from results obtained by the technical staff.

\section{Results}

Tables 1 and 2 summarise the results obtained for the $\stackrel{\mathbb{D}}{\stackrel{2}{\varrho}}$ precision and comparison studies. For three of the four analysers (Reflotron, Seralyzer, and Vision), the $\vec{P}$ performance of nurses was better than that of physicians and medical office personnel: The CVs $\vec{\omega}$ obtained by nurses for one analyser (Vision), were not significantly different from those obtained by the 용 technical staff. The better performance of the nurses $A$ was further reflected when the difference between test $\vec{i}$

Table 1 Comparison of precision of results obtained by non-specialist and specialist personnel

\begin{tabular}{|c|c|c|c|c|}
\hline \multirow[b]{2}{*}{ Analyser and test } & \multicolumn{4}{|c|}{ CV\% obtained by: } \\
\hline & Nurses & $\begin{array}{l}\text { Medical office } \\
\text { personnel }\end{array}$ & Physicians & $\begin{array}{l}\text { Technical } \\
\text { staff }\end{array}$ \\
\hline $\begin{array}{l}\text { Refiotron: } \\
\text { Glucose } \\
\text { Cholesterol } \\
\text { Triglycerides } \\
\text { Gamma glutamyl transferase } \\
\text { (Mean precision) }\end{array}$ & $\begin{array}{c}4 \cdot 3 \\
4 \cdot 4 \\
3 \cdot 0 \\
2 \cdot 8 \\
(3 \cdot 7)\end{array}$ & $\begin{array}{c}3.4 \\
3.0 \\
3.4 \\
6.9 \\
(4 \cdot 2)\end{array}$ & $\begin{array}{c}4 \cdot 7 \\
4 \cdot 6 \\
4 \cdot 8 \\
6 \cdot 6 \\
(5 \cdot 2)\end{array}$ & $\begin{array}{c}1.8 \\
3.4 \\
2.7 \\
3.0 \\
(2.7)\end{array}$ \\
\hline $\begin{array}{l}\text { Seralyzer: } \\
\text { Creatinine } \\
\text { Glucose } \\
\text { Potassium } \\
\text { Aspartate aminotransferase } \\
\text { (Mean precision) }\end{array}$ & $\begin{array}{c}8 \cdot 4 \\
4 \cdot 1 \\
5 \cdot 1 \\
14 \cdot 1 \\
(9 \cdot 4)\end{array}$ & $\begin{array}{r}14 \cdot 1 \\
12 \cdot 8 \\
8 \cdot 8 \\
19.9 \\
(13.9)\end{array}$ & $\begin{array}{r}17.8 \\
6.4 \\
7.0 \\
9.2 \\
(10.1)\end{array}$ & $\begin{array}{c}5 \cdot 8 \\
4 \cdot 0 \\
5 \cdot 9 \\
5 \cdot 1 \\
(5 \cdot 2)\end{array}$ \\
\hline $\begin{array}{l}\text { Vision: } \\
\text { Glucose } \\
\text { Urea } \\
\text { Cholesterol } \\
\text { Triglycerides } \\
\text { Alkaline phosphatase } \\
\text { Uric acid } \\
\text { (Mean precision) }\end{array}$ & $\begin{array}{c}1 \cdot 8 \\
2 \cdot 2 \\
1.8 \\
1.5 \\
1.8 \\
2 \cdot 2 \\
(1 \cdot 9)\end{array}$ & $\begin{array}{l}1 \cdot 7 \\
2 \cdot 2 \\
1 \cdot 9 \\
4 \cdot 0 \\
2 \cdot 6 \\
2 \cdot 9 \\
(2 \cdot 5)\end{array}$ & $\begin{array}{l}2 \cdot 8 \\
3 \cdot 4 \\
3 \cdot 3 \\
4 \cdot 6 \\
2 \cdot 4 \\
2 \cdot 6 \\
(3 \cdot 2)\end{array}$ & $\begin{array}{l}1 \cdot 5 \\
2 \cdot 8 \\
1 \cdot 3 \\
2 \cdot 5 \\
2 \cdot 0 \\
2 \cdot 0 \\
(2 \cdot 0)\end{array}$ \\
\hline $\begin{array}{l}\text { DT60: } \\
\text { Sodium } \\
\text { Potassium } \\
\text { Glucose } \\
\text { Amylase } \\
\text { Urate } \\
\text { Creatinine } \\
\text { (Mean precision) }\end{array}$ & $\begin{array}{r}2 \cdot 9 \\
3 \cdot 8 \\
3 \cdot 7 \\
12 \cdot 2 \\
4 \cdot 9 \\
13 \cdot 5 \\
(6 \cdot 8)\end{array}$ & $\begin{array}{r}1 \cdot 7 \\
1 \cdot 8 \\
4 \cdot 2 \\
8 \cdot 8 \\
3 \cdot 7 \\
15 \cdot 2 \\
(5 \cdot 9)\end{array}$ & $\begin{array}{c}2 \cdot 7 \\
4 \cdot 2 \\
3 \cdot 6 \\
13 \\
4 \cdot 2 \\
8 \cdot 4 \\
(4 \cdot 3)\end{array}$ & $\begin{array}{l}1.9 \\
1.0 \\
1.2 \\
4 \cdot 3 \\
0.9 \\
6 \cdot 9 \\
(2 \cdot 7)\end{array}$ \\
\hline
\end{tabular}

Table 2 No $(\%)^{*}$ of results that differed by more than $10 \%$ from results obtained by technical staff

\begin{tabular}{|c|c|c|c|}
\hline Instrument & Nurses & Medical office personnel & Physicians \\
\hline $\begin{array}{l}\text { Reflotron } \\
\text { Seralyzer } \\
\text { Vision } \\
\text { DT60 }\end{array}$ & $\begin{array}{cc}2 / 68 & (2 \cdot 9) \\
16 / 68 & (23 \cdot 5) \\
0 / 108(0) & (0) \\
18 / 108(16 \cdot 7)\end{array}$ & $\begin{array}{c}4 / 56 \quad(7 \cdot 1) \\
35 / 84(41 \cdot 7) \\
2 / 108(1 \cdot 8) \\
22 / 106(20 \cdot 7)\end{array}$ & $\begin{array}{c}13 / 75(17 \cdot 3) \\
44 / 100(44) \\
0 / 108(0) \\
19 / 104(18 \cdot 3)\end{array}$ \\
\hline
\end{tabular}

*Percentage difference calculated as: (result obtained by technical staff - result obtained by nurse, physician, etc) - (result obtained by technical $\Omega$ staff) $\times 100$. 
values obtained by the trained technical staff and other groups was considered. For the same three analysers, the nurses had the lowest number of results that were more than $10 \%$ different from results obtained by the technical staff.

The difference in numbers of test results between the technical staff and other groups was also a reflection of how easy the analysers were to use. The Vision analyser requires minimal technical skills; only two of the 320 tests differed by more than $10 \%$ between the technical staff and other groups. On the other hand, the Seralyzer, which requires pipetting and dilutions and hence some manual dexterity, had 95 of 254 results which differed by more than $10 \%$ between technical staff and others. The Reflotron analyser is also relatively simple to use and gave 19 of 199 results more than $10 \%$ different. The DT60 had 59 of 318 of such results.

The DT60 analyser requires serum or plasma to be pipetted on to a slide; this step probably accounts for most of the results (59 of 318) which were more than $10 \%$ different. The creatinine method, which is a two slide procedure, and therefore increases the likelihood of error, accounted for a large portion of the errors (34 of 54). After creatinine was excluded the error rate decreased to $9 \cdot 0 \%$ (24 of 264$)$.

The results obtained by the above analysers correlated extremely well with reference laboratory methods when tests were performed by a technical staff member. ${ }^{4-6}$ The correlation between precision for each test and percentage of results more than $10 \%$ different from those obtained by technical staff was $0.95(p<0.01)$. This indicates internal consistency of our results - that is, those tests which showed greater degree of imprecision had the larger percentage of tests which differed from those obtained by the technical staff.

\section{Discussion}

Our study shows that in most cases results obtained for at least three of the four analysers provided reliable results when used in decentralised sites. The better results obtained by nurses is probably a reflection of either their superior manual dexterity or familiarity with performing other technical procedures on wards and in clinics, such as urinalysis and glucose testing.

The difference in results obtained between the technical staff and other non-technical groups also depends on the type of analyser used. At one extreme the Vision analyser requires very little technical expertise beyond filling a capillary tube with blood, serum, or plasma. The results obtained by nurses, physicians, and medical office personnel were almost all within $10 \%$ of those obtained by technologists. On the other hand, the Seralyzer requires accurate pipetting and dilutions which are obviously prone to error in the hands of inexperienced staff. As might be expected, almost one in three results obtained by technical staff differed by more than $10 \%$ from results obtained by the other groups.

It is important to realise that each of the participants received only minimal training on the instrument and that performance would probably be even better with further training and practice. As often happens in clinical settings, however, after the initial training of a few motivated people, the rest receive only minimal training. Thus after a few months of operation these analysers will probably be operated by several poorly trained or untrained staff members.

Our study shows that even in the extreme setting of minimally trained personnel, reliable results can be obtained with analysers which require minimal technical expertise; less reliable results are obtained when steps such as dilutions and pipetting are necessary.

A final but most important point is that specimens of body fluids-for chemical analysis present infectious hazards. Most trained technologists are aware of these hazards, and follow strict guidelines concerning ways in which to reduce the risks. Such guidelines include the transport of potentially infectious material properly packaged and labelled, the need to wear protective clothing, and correct methods for opening specimen tubes and lyophilised control material. Nontechnical personnel clearly do not have this training and the issue of safety in the decentralised settings we have described will have to be carefully considered.

This work was supported by a grant from the Department of National Health and Welfare, Canada. We appreciate the cooperation of nurses, physicians, and medical office personnel who participated in the study and the technical assistance of Susan Gold and Francine Sincennes.

\section{References}

1 Belsey R, Baer D, Sewell D. Laboratory test analysis near the patient. JAMA 1986;255:785-6.

2 Marks V. Clinical biochemistry nearer the patient. Br Med J 1983;286:1166-7.

3 Crawley R, Belsey R, Brock D, Baer DM. Regulation of physician office laboratories. JAMA 1986;255:374-82.

4 Nanji AA, Sincennes F, Poon R, Hinberg I. Evaluation of Reflotron analyzer. Clin Chem (in press).

5 Nanji AA, Sincennes F, Poon R, Hinberg I. Evaluation of the Kodak DT60 analyzer. Clin Chem (in press).

6 Nanji AA, Sincennes F, Poon R, Hinberg I. Evaluation of the Ames Seralyzer. Clin Chem (in press).

Requests for reprints to: Dr Amin A Nanji, Department of Laboratory Medicine, Ottawa General Hospital, 501 Smyth Road, Ottawa, Ontario K1H 8L6, Canada. 